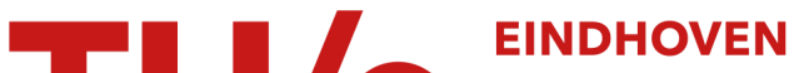

\section{A high-voltage pulse transformer with a modular ferrite core}

\section{Citation for published version (APA):}

Liu, Z., Winands, G. J. J., Yan, K., Pemen, A. J. M., \& Heesch, van, E. J. M. (2008). A high-voltage pulse transformer with a modular ferrite core. Review of Scientific Instruments, 79(1), 015104-1/5.

https://doi.org/10.1063/1.2830943

DOI:

$10.1063 / 1.2830943$

Document status and date:

Published: 01/01/2008

\section{Document Version:}

Publisher's PDF, also known as Version of Record (includes final page, issue and volume numbers)

\section{Please check the document version of this publication:}

- A submitted manuscript is the version of the article upon submission and before peer-review. There can be important differences between the submitted version and the official published version of record. People interested in the research are advised to contact the author for the final version of the publication, or visit the $\mathrm{DOI}$ to the publisher's website.

- The final author version and the galley proof are versions of the publication after peer review.

- The final published version features the final layout of the paper including the volume, issue and page numbers.

Link to publication

\section{General rights}

Copyright and moral rights for the publications made accessible in the public portal are retained by the authors and/or other copyright owners and it is a condition of accessing publications that users recognise and abide by the legal requirements associated with these rights.

- Users may download and print one copy of any publication from the public portal for the purpose of private study or research.

- You may not further distribute the material or use it for any profit-making activity or commercial gain

- You may freely distribute the URL identifying the publication in the public portal.

If the publication is distributed under the terms of Article 25fa of the Dutch Copyright Act, indicated by the "Taverne" license above, please follow below link for the End User Agreement:

www.tue.nl/taverne

Take down policy

If you believe that this document breaches copyright please contact us at:

openaccess@tue.nl

providing details and we will investigate your claim. 


\title{
A high-voltage pulse transformer with a modular ferrite core
}

\author{
Z. Liu ${ }^{\mathrm{a})}$ and G. J. J. Winands \\ EPS Group, Electrical Department, Technology University of Eindhoven, P.O. Box 513, 5600 MB Eindhoven, \\ The Netherlands \\ K. Yan \\ Department of Environmental Science, Zhejiang University, Hangzhou 310027, People's Republic of China
}

\begin{abstract}
A. J. M. Pemen and E. J. M. Van Heesch
EPS Group, Electrical Department, Technology University of Eindhoven, P.O. Box 513, 5600 MB Eindhoven, The Netherlands
\end{abstract}

(Received 19 November 2007; accepted 11 December 2007; published online 11 January 2008)

\begin{abstract}
A high ratio (winding ratio of 1:80) pulse transformer with a modular ferrite core was developed for a repetitive resonant charging system. The magnetic core is constructed from 68 small blocks of ferrites, glued together by epoxy resin. This allows a high degree of freedom in choosing core shape and size. Critical issues related to this modular design are the size tolerance of the individual ferrite blocks, the unavoidable air gap between the blocks, and the saturation of the core. To evaluate the swing of the flux density inside the core during the charging process, an equivalent circuit model was introduced. It was found that when a transformer is used in a resonant charging circuit, the minimal required volume of the magnetic material to keep the core unsaturated depends on the coupling coefficient of the transformer and is independent of the number of turns of the primary winding. Along the flux path, 17 small air gaps are present due to the inevitable joints between the ferrite blocks. The total air gap distance is about $0.67 \mathrm{~mm}$. The primary and secondary windings have 16 turns and 1280 turns, respectively, and the actually obtained ratio is about 1:75.4. A coupling coefficient of $99.6 \%$ was obtained. Experimental results are in good agreement with the model, and the modular ferrite core works well. Using this transformer, the high-voltage capacitors can be charged up to more than $70 \mathrm{kV}$ from a low-voltage capacitor with an initial charging voltage of about $965 \mathrm{~V}$. With $26.9 \mathrm{~J}$ energy transfer, the increased flux density inside the core was about $0.23 \mathrm{~T}$, and the core remains unsaturated. The energy transfer efficiency from the primary to the secondary was around 92\%. () 2008 American Institute of Physics. [DOI: 10.1063/1.2830943]
\end{abstract}

\section{INTRODUCTION}

Transformers are often used in pulsed power systems to resonantly step up the charging voltage. It can be either an air core transformer or a magnetic core transformer. For an air core transformer, there is no saturation problem, and it is lightweight and easy to construct. However, the coupling coefficient $k$ is low (normally $k$ is less than 0.8 ). ${ }^{1,2}$ To obtain an efficient energy transfer, the air core transformer is normally used in dual resonant mode, i.e., as a Tesla transformer. ${ }^{3}$ And at least one primary oscillation cycle is needed to accomplish the charging process (when $k=0.6){ }^{4}$ Moreover, the charging voltage is bipolar, which makes it difficult to use semiconductor switches [thyristor, insulated gate bipolar transistor (IGBT), and metal-oxide-semiconductor field effect transistor (MOSFET)] or magnetic switches. When a magnetic core is used, a high coupling coefficient $(k>0.99)$ can be obtained. ${ }^{5,6}$ By using the magnetic transformer in a resonant charging circuit, an efficient energy transfer can be accomplished within only half a primary oscillation cycle, i.e., in single resonant mode.

One critical issue associated with a magnetic core transformer is the saturation of the core. Though the coupling

${ }^{a)}$ Electronic mail: z.liu@tue.nl. coefficient of a magnetic core transformer is high, it is always less than 1 . In a resonant charging circuit, the unavoidable leakage inductance of the transformer affects the charging time and thus also affects the flux density in the core. The influence of the coupling coefficient $k$ on the flux density in the core has never been reported in literature. In this paper, an equivalent circuit model is introduced to analyze the effect of the coupling coefficient $k$ on the swing of the flux density in the core of a transformer during one charging cycle. Based on this model, a high ratio (winding ratio of 1:80) magnetic transformer was developed. Ferrite blocks were adopted to make the core. Totally 68 small blocks were used and glued together by epoxy resin. Along the magnetic path of the core, 17 small air gaps are present due to the inevitable joints between the blocks. The transformer was successfully applied in a repetitive resonant charging system. It was found that the modular ferrite core works well and that the transformer meets the design requirements. Detailed information about the effect of the coupling coefficient $k$, the design of the transformer, and the experimental results will be presented.

\section{EFFECT OF THE COUPLING COEFFICIENT K ON THE CORE VOLUME}

Figure 1 shows the resonant charging circuit and its equivalent circuits. The resonant circuit, as shown in Fig. 


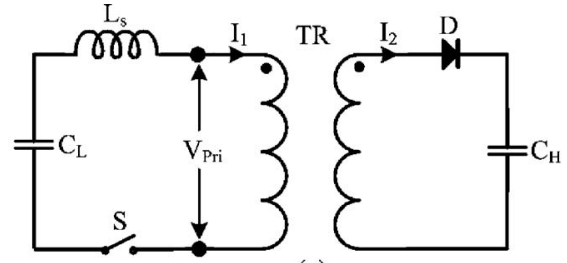

(a)

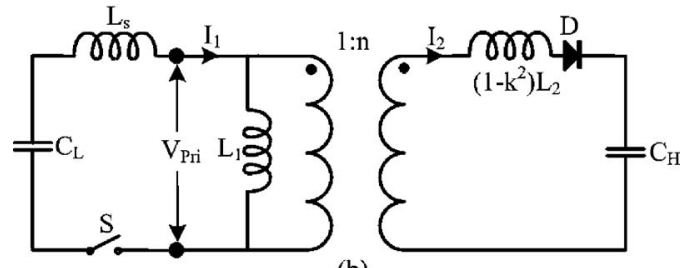

(b)

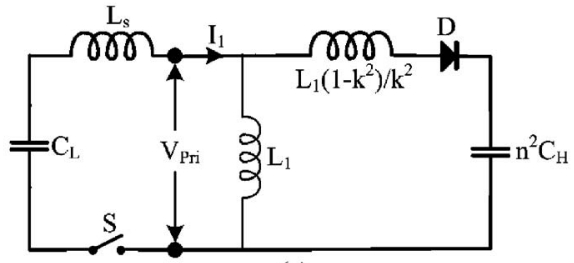

(c)

FIG. 1. (a) the resonant charging circuit; (b) the transformer is represented by an ideal transformer combined with two uncoupled inductors; (c) the simplified equivalent circuit, where the components at the secondary side are transferred to the primary side.

1(a), includes a low-voltage capacitor $C_{L}$, a stray inductor $L_{s}$ (introduced by the connection leads), a transformer TR, a switch $\mathrm{S}$, a diode $\mathrm{D}$, and a high voltage capacitor $C_{H}$. The transformer TR can be represented by an ideal transformer in combination with two uncoupled inductors, ${ }^{7}$ as shown in Fig. 1(b), where $L_{1}$ and $L_{2}$ are the primary and secondary inductances of the transformer TR, respectively. $k$ is the coupling coefficient of the transformer TR and is equal to $M / \sqrt{L_{1} L_{2}}$ ( $M$ is the mutual inductance of the transformer), and $n$ is the ratio of the transformer and is equal to $M / L_{1}$ or $k \sqrt{L_{2} / L_{1}}$. By transferring the inductance $\left(1-k^{2}\right) L_{2}$ and capacitor $C_{H}$ to the primary side of the transformer TR, one may derive the equivalent circuit shown in Fig. 1(c).

When the coupling coefficient $k$ is large enough, $L_{1}$ will be significantly larger than the inductance $L_{1}\left(1-k^{2}\right) / k^{2}$. And thus most of the energy from $C_{L}$ will be transferred into $n^{2} C_{H}$ and only a small part will be absorbed by $L_{1}$ during one charging cycle. Ignoring $L_{1}$ and energy losses during the charging cycle, one can derive the following expressions for the situation that $C_{L}=n^{2} C_{H}$ according to the model shown in Fig. 1(c).

$$
\begin{aligned}
& V_{\mathrm{Pri}}(t)=\frac{V_{0}}{2}\left(1+\frac{L-L_{s}}{L+L_{s}} \cos \omega t\right), \quad 0 \leqslant \omega t \leqslant \pi \\
& \Delta T=\pi \sqrt{\left(L_{s}+L\right) C} \\
& \Delta B=\frac{1}{A N_{1}} \int_{0}^{\Delta T} V_{\mathrm{Pri}}(t) d t=\frac{\pi V_{L} \sqrt{C L_{1}}}{2 N_{1} A} \sqrt{\frac{L_{s}}{L_{1}}+\left(\frac{1}{k^{2}}-1\right)} .
\end{aligned}
$$

In the above equations, $V_{\mathrm{Pri}}(t), V_{0}, \Delta T$, and $\Delta B$ are the voltage at the primary side of the transformer, the initial voltage on $C_{L}$, the charging time, and the incremental flux density inside the core, respectively. $L$ is the leakage inductance of TR and is equal to $L_{1}\left(1-k^{2}\right) / k^{2}$, and $C=C_{L} / 2 . A$ and $N_{1}$ are the cross section of the core and the number of turns of the primary winding, respectively. The inductance of the primary winding can be approximated as

$$
L_{1}=\frac{N_{1}^{2} \mu A}{\ell} \text {. }
$$

In Eq. (4), $\mu$ and $\ell$ are the permeability of the core and the mean length of the magnetic path, respectively. Substituting Eq. (4) into Eq. (3), one may derive the relationship between $\Delta B$ and the volume of the core $[A \ell]$.

$$
\Delta B=\frac{\pi}{2} \sqrt{\frac{\mu E}{A \ell}} \sqrt{\frac{L_{s}}{L_{1}}+\left(\frac{1}{k^{2}}-1\right)},
$$

where $E$ is the energy transferred per pulse and equal to $C V_{0}^{2}$. From Eq. (5), it can be seen that $\Delta B$ is a function of the energy transferred per pulse $E$, the volume of the core $[A \ell]$, the ratio of $L_{s}$ to $L_{1}$, and the coupling coefficient $k$.

For proper operation, $\Delta B$ must be less than the allowable swing of the flux density $\Delta B_{m}$ of the applied magnetic material. And therefore the volume of the core must be designed according to the following condition:

$$
\begin{aligned}
{[A \ell] } & \geqslant \frac{\pi^{2} \mu E}{4 \Delta B_{m}^{2}}\left[\frac{L_{s}}{L_{1}}+\left(\frac{1}{k^{2}}-1\right)\right]>\frac{\pi^{2} \mu E}{4 \Delta B_{m}^{2}}\left(\frac{1}{k^{2}}-1\right) \\
& =[A \ell]_{\text {critical }} .
\end{aligned}
$$

From the above equation, one can see that the volume of the core must be larger than a critical volume $[A \ell]_{\text {critical }}$, which is determined by the coupling coefficient $k$.

It is noted that the calculated values for $\Delta T$ and $\Delta B$ on the basis of the model described above are a little larger than the actual values. The higher the coupling coefficient $k$, the less the difference becomes. Especially when $k>99 \%$, the differences for $\Delta T$ and $\Delta B$ are less than $0.5 \%$ and $1.4 \%$ respectively.

\section{DESIGN AND CONSTRUCTION}

The transformer is designed for a resonant charging system $^{8}$ to charge the high-voltage capacitor $C_{H}$ (about $10 \mathrm{nF}$ ) to a voltage of $70 \mathrm{kV}$, where the low-voltage capacitor $C_{L}$ is initially charged to about $1 \mathrm{kV}$. Thus the voltage transfer ratio of the transfer needs to be at least 1:70; actually the winding ratio was chosen to be $1: 80$. Ferrite blocks were used to construct the core. With regard to the ferrite material, the relative permeability, the saturation flux density, and the residual flux density are $2400,0.5 \mathrm{~T}$, and $0.15 \mathrm{~T}$, respectively. The dimensions of each ferrite block are $5 \times 5$ $\times 10 \mathrm{~cm}^{3}$. The ferrite blocks are glued together by epoxy resin to obtain the desired core shape and dimensions. The advantage of using discrete ferrite blocks is the flexibility in construction of various kinds of cores ( $C$ type or shell type) with various dimensions. 


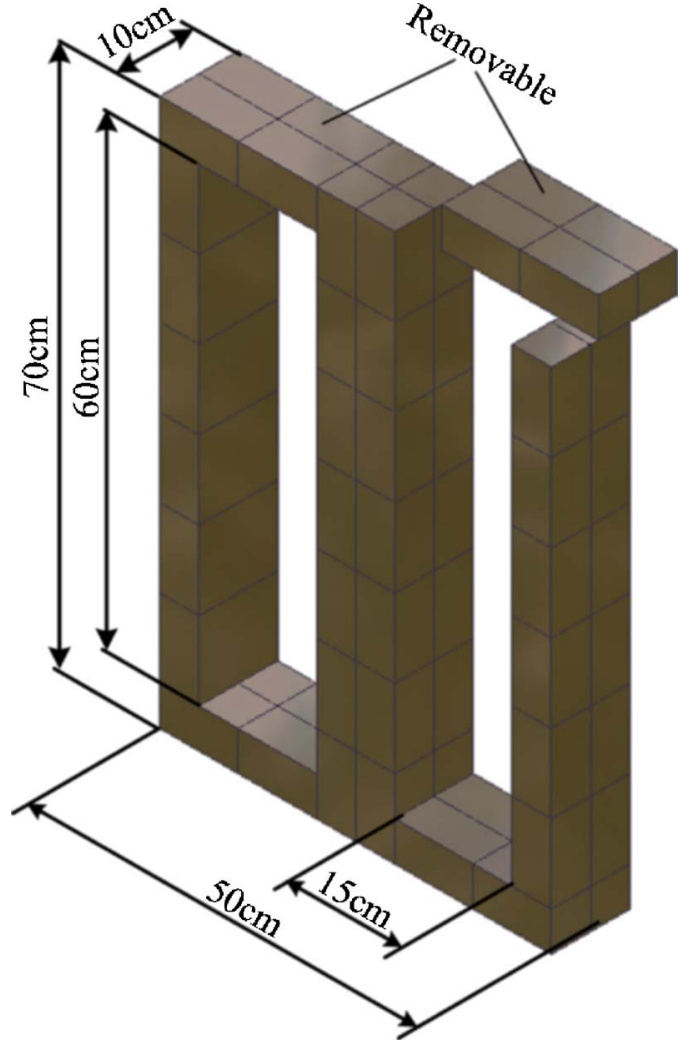

FIG. 2. (Color online) Transformer core.

\section{A. Determine the volume of the core}

To estimate the critical volume of the ferrite core according to Eq. (6), some assumptions were made: (i) The stray capacitance of the transformer is assumed to be around $0.5 \mathrm{nF}$ and is added to the high voltage capacitor $C_{H}$. So $C_{H}$ becomes $10.5 \mathrm{nF}$; thus under the matching condition $C_{L}=n^{2} C_{H}$, the transferred energy per pulse $E$ is about $33 \mathrm{~J}$ at $V_{0}=1 \mathrm{kV}$. (ii) According to the specification of the used ferrite material, the allowable swing of the flux density is $0.35 \mathrm{~T}$; in this design, a value of $\Delta B_{m}=0.3 \mathrm{~T}$ was used. (iii) The coupling coefficient $k$ and the relative permeability $\mu_{r}$ of the core were empirically determined to be 0.996 and 1200 , respectively. Under these assumptions, from Eq. (6), the critical volume of the core was estimated to be $11190 \mathrm{~cm}^{3}$, which means that at least 45 ferrite blocks are needed. Due to the stray inductance and to ensure the proper operation of the transformer 68 ferrite blocks were actually used. By gluing these blocks together with epoxy resin, a shell-type core was made, as shown in Fig. 2. The size of the core is $50 \times 10$ $\times 70 \mathrm{~cm}^{3}$; other dimensions are shown in Fig. 2. Except for the two removable blocks on the top, all blocks are glued together. The mean length of the magnetic path is $1.7 \mathrm{~m}$. Along the magnetic path, 17 air gaps are present due to the inevitable joints between the blocks. The initially predicted total length of the 17 gaps is between 0.5 and $1 \mathrm{~mm}$.

\section{B. Select the number of turns of the primary winding}

The number of turns of the primary winding $N_{1}$ was chosen according to the specification of the resonant charging system. To keep the charging system within the safe re-
TABLE I. Evaluation of the design when $N_{1}=16$.

\begin{tabular}{lll}
\hline \hline & \multicolumn{2}{c}{ The total distance of gaps } \\
\cline { 2 - 3 } \multicolumn{1}{c}{$\mathrm{K}=99.6 \%$} & $1 \mathrm{~mm}$ & $0.5 \mathrm{~mm}$ \\
\hline Equivalent $\mu_{i}$ & 995.4 & 1407 \\
Primary inductance $L_{1}$ & $1.88 \mathrm{mH}$ & $2.66 \mathrm{mH}$ \\
Leakage inductance $L$ & $15.15 \mu \mathrm{H}$ & $21.42 \mu \mathrm{H}$ \\
Charging time $\Delta T$ & $70.9 \mu \mathrm{s}$ & $84.3 \mu \mathrm{s}$ \\
Incremental density $\Delta B$ & $0.22 \mathrm{~T}$ & $0.26 \mathrm{~T}$ \\
Peak primary current & $1.49 \mathrm{kA}$ & $1.25 \mathrm{kA}$ \\
\hline \hline
\end{tabular}

gion, the maximum primary current must be less than the current rating $(2 \mathrm{kA})$ of the thyristor switch used in the resonant charging system. Based on the model shown in Fig. 1(c), with the assumptions of $k=0.996$ and $L_{s}=0$ the peak primary current was estimated for different turn numbers from 10 to 20. These estimations were made for two different total lengths of air gaps, i.e., 1 and $0.5 \mathrm{~mm}$, respectively. The primary turn number $N_{1}=16$ was chosen, since for this value the primary peak current will stay within safe margins. In addition, other parameters, e.g., the equivalent $\mu_{r}$, primary inductance $L_{1}$, etc., were evaluated when $N_{1}=16$, as shown in Table I. The transformer will operate properly with $N_{1}=16$, provided that the total length of air gaps could be controlled between 0.5 and $1 \mathrm{~mm}$.

\section{Construction}

The 16-turn primary winding was made from copper foil with a thickness of $1 \mathrm{~mm}$ and a width of $29 \mathrm{~mm}$. The windings are wound on a square bobbin made from fiberglass. The secondary winding has a turn number of 1280 and is wound on a cone-shaped fiberglass bobbin. It was made from copper wire with a diameter of $0.42 \mathrm{~mm}$. To reduce the winding resistance, two parallel layers were used. They were interconnected at the middle (i.e., the top layer goes to the bottom and the bottom layer goes to the top). Both the primary and the secondary are placed around the middle leg of the core. An aluminum cylindrical screen with a $1 \mathrm{~cm}$ split was positioned between the primary and secondary windings, in order to prevent the capacitive coupling between the primary and the secondary. The secondary winding is equipped with a round ring to control the high electric field. The two outer legs of the core are also provided with fieldcontrol aluminum parts. The whole transformer is supported by a wooden frame. A photo of the transformer is shown in Fig. 3. This transformer is immersed into transformer oil. The measured parameters are shown in Table II. According to the primary inductance, the effective values for $\mu_{r}$ and the total length of the air gaps are estimated to be 1238 and $0.665 \mathrm{~mm}$, respectively. These values are within the estimated ranges shown in Table I. A coupling coefficient of 99.62\% was obtained, and the actual ratio $n$ is about 1:75.4.

\section{EXPERIMENTAL RESULTS ON A RESONANT CHARGING SYSTEM}

The designed transformer (TR) was applied within a setup as shown in Fig. 4. It consists of a resonant charging 


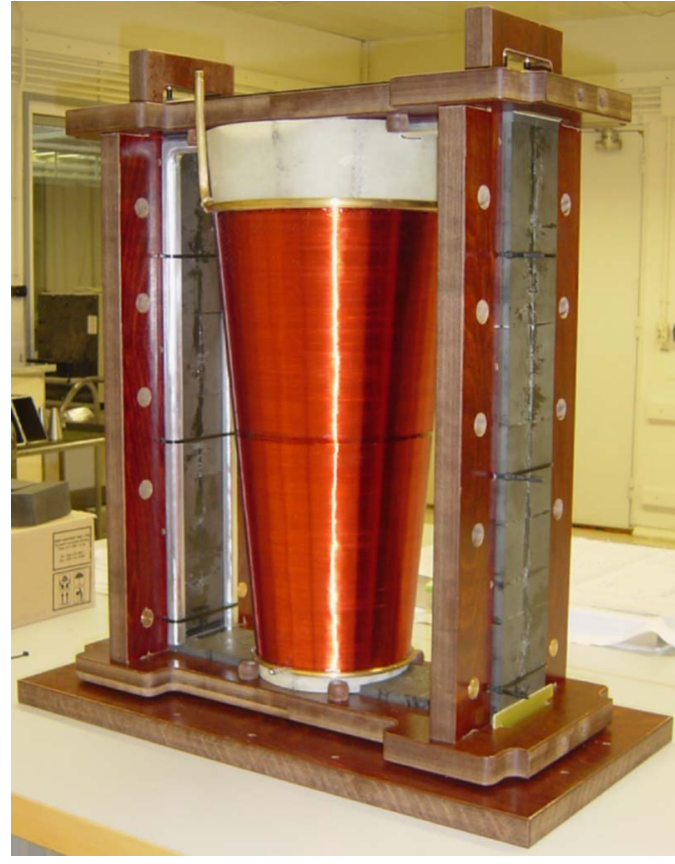

FIG. 3. (Color online) Photo of the transformer.

unit $^{8}$ and a high-voltage pulser. The high-voltage pulser includes a high-voltage capacitor $C_{H}$, a switch $\mathrm{S}$, an $L C R$ trigger circuit, and a resistive load (about $82 \Omega$ ). The switch $\mathrm{S}$ is a multiple-gap spark gap switch ${ }^{9}$ consisting of three $9 \mathrm{~mm}$ gaps. The LCR trigger circuit ${ }^{10}$ consists of an inductor $L$, a capacitor $C$, and a resistor $R$. Detailed information about the mechanism of the $L C R$ trigger circuit was reported previously. ${ }^{10}$ The value of the high-voltage capacitor $C_{H}$ is $10.37 \mathrm{nF}$.

The principle of the resonant charging system was comprehensively discussed previously. ${ }^{8}$ Initially, the storage capacitor $C_{0}$ is charged up to $V_{0}(\sim 535 \mathrm{~V})$. The system accomplishes one charging cycle in three steps. First, by closing thyristor $\mathrm{Th}_{1}$, the capacitor $C_{L}$ is charged to about $1 \mathrm{kV}$ by the storage capacitor $C_{0}$. Second, after the charging of $C_{L}$ is finished and thyristor $\mathrm{Th}_{1}$ is switched off, by closing thyristor $\mathrm{Th}_{2}$ the capacitor $C_{H}$ is charged by $C_{L}$ via the transformer TR. Then, after the charging of $C_{H}$ is finished and thyristor $\mathrm{Th}_{2}$ is switched off, $C_{H}$ is discharged into the load via the spark gap switch S. Finally with thyristor $\mathrm{Th}_{3}$ the polarity of the remaining voltage on $C_{L}$ can be reversed before the next charging cycle.

Figure 5 shows typical voltages on the capacitors $C_{L}$ and $C_{H}$, respectively during one charging cycle when $C_{L}=60.6 \mu \mathrm{F}$, and $C_{H}=10.37 \mathrm{nF}$. The low-voltage capacitor

TABLE II. Measured parameters of the transformer.

\begin{tabular}{ll}
\hline \hline Primary inductance $L_{1}$ & $2.34 \mathrm{mH}$ \\
Secondary inductance $L_{2}$ & $13.46 \mathrm{H}$ \\
Coupling coefficient $k$ & $99.62 \%$ \\
Actual ratio $n$ & 75.4 \\
Primary winding resistance $R_{P}$ & $9.63 \mathrm{~m} \Omega$ \\
Secondary winding resistance $R_{S}$ & $80.35 \Omega$ \\
Primary stray capacitance $C_{P}$ & $2.4 \mathrm{nF}$ \\
Secondary stray capacitance $C_{S}$ & $680 \mathrm{pF}$ \\
\hline \hline
\end{tabular}

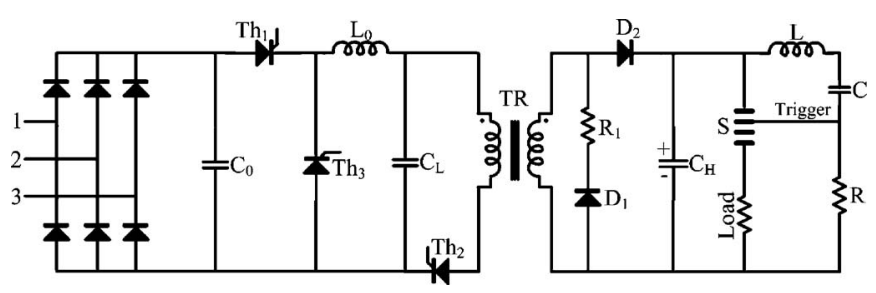

FIG. 4. The schematic diagram of the experimental setup.

$C_{L}$ was charged up to $965 \mathrm{~V}$ from an initial voltage of $16 \mathrm{~V}$. After closing thyristor $\mathrm{Th}_{2}$, the voltage on $C_{L}$ dropped to $16 \mathrm{~V}$ again, and the high-voltage capacitor $C_{H}$ was charged up to $70.3 \mathrm{kV}$ within a charging time of $79 \mu \mathrm{s}$, which implies that the designed transformer meets the voltage requirement.

Figure 6 shows the typical voltage and current on the primary winding of the transformer when $C_{L}=60.6 \mu \mathrm{F}$ and $C_{H}=10.37 \mathrm{nF}$. It can be seen that the peak value of the primary current is $1.14 \mathrm{kA}$. This is about $57 \%$ of the current rating $(2 k A)$ of thyristor $\mathrm{Th}_{2}$, which indicates that the design of the transformer ensured the switch to be used safely. Furthermore, according to the current waveform shown in Fig. 6 , the charging time is about $79 \mu \mathrm{s}$. The leakage inductance of the transformer $L_{1}\left(1-k^{2}\right) / k^{2}$ is about $17.8 \mu \mathrm{H}$, and the stray inductance $L_{S}$ of the present system is approximately $2.9 \mu \mathrm{H}$. By integrating the primary voltage shown in Fig. 6, the swing of the flux density inside the core can be estimated. The result is shown in Fig. 7. It can be found, that when the charging is finished, the increased flux density inside the core is $0.23 \mathrm{~T}$, which means that no saturation will occur for the present design of the transformer when the charging is complete. This value is in good agreement with the theoretical value of $0.232 \mathrm{~T}$ given by Eq. (5). The further increase of the flux density after the charging has been finished is caused by the voltage oscillation between the primary and the secondary (as shown in Fig. 6).

The total energy conversion efficiency $\eta$ of the transformer was evaluated by the following equation:

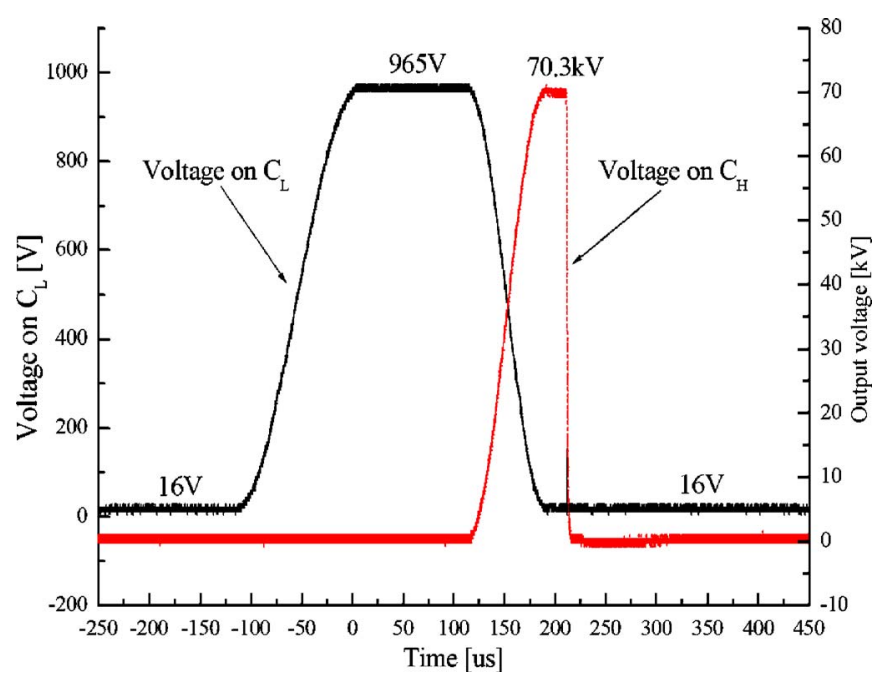

FIG. 5. (Color online) Typical voltages on $C_{L}$ and $C_{H}$ during one charging cycle when $C_{L}=60.6 \mu \mathrm{F}$ and $C_{H}=10.37 \mathrm{nF}$. 


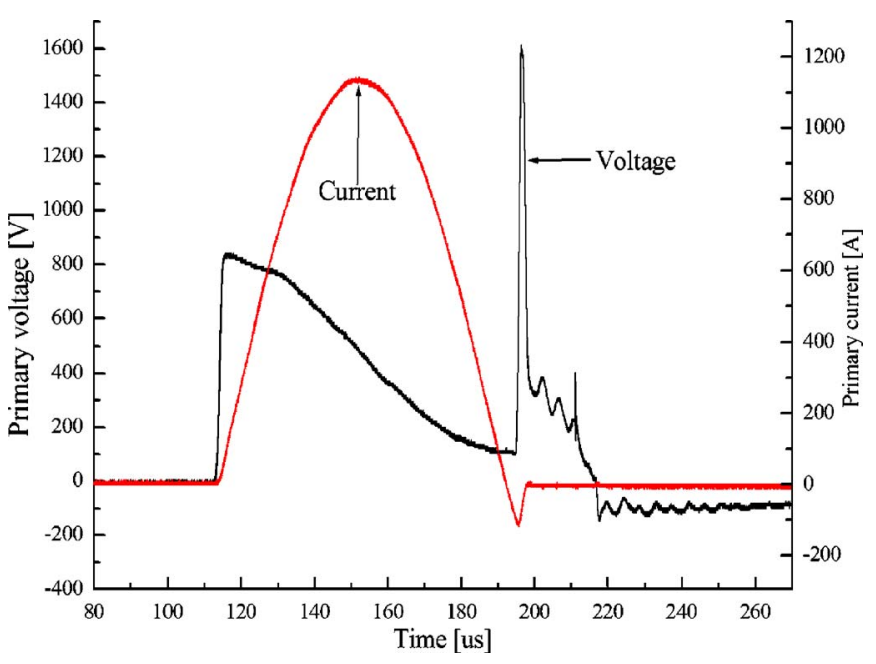

FIG. 6. (Color online) The typical voltage and current on the primary of the transformer when $C_{L}=60.6 \mu \mathrm{F}$ and $C_{H}=10.37 \mathrm{nF}$.

$$
\eta=\frac{E_{\text {out }}}{E_{\text {in }}}=\frac{\int V_{H}(t) I_{H}(t) d t}{\int V_{\mathrm{Pri}}(t) I_{\mathrm{Pri}}(t) d t},
$$

where $E_{\text {in }}$ and $E_{\text {out }}$ refer to the energy input into the transformer and the energy output from the transformer, namely, the energy flowed out from the diode $\mathrm{D}_{2} . V_{\mathrm{Pri}}(t), V_{H}(t)$, $I_{\mathrm{Pri}}(t)$, and $I_{H}(t)$ refer to the voltage across the primary of the transformer, the voltage on $C_{H}$, the current in the primary of the transformer, and the current at the secondary of the transformer, respectively. These four parameters were measured simultaneously when $C_{L}=60.6 \mu \mathrm{F}$. The calculated values of $E_{\text {in }}$ and $E_{\text {out }}$ are given in Fig. 8. When the charging finished,

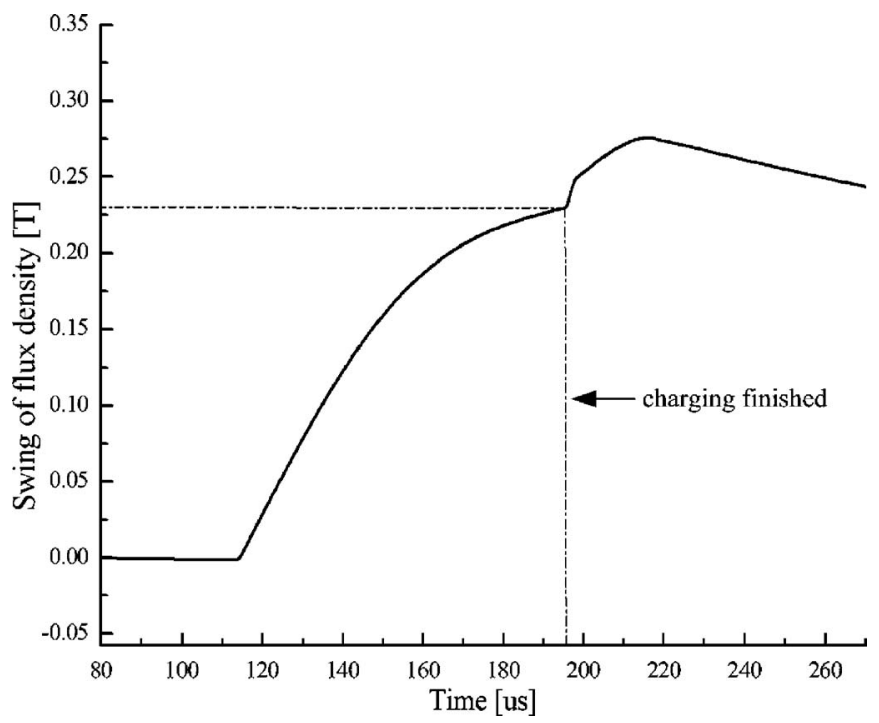

FIG. 7. The swing of the flux density $\Delta B$ inside the core when $C_{L}=60.6 \mu \mathrm{F}$ and $C_{H}=10.37 \mathrm{nF}$.

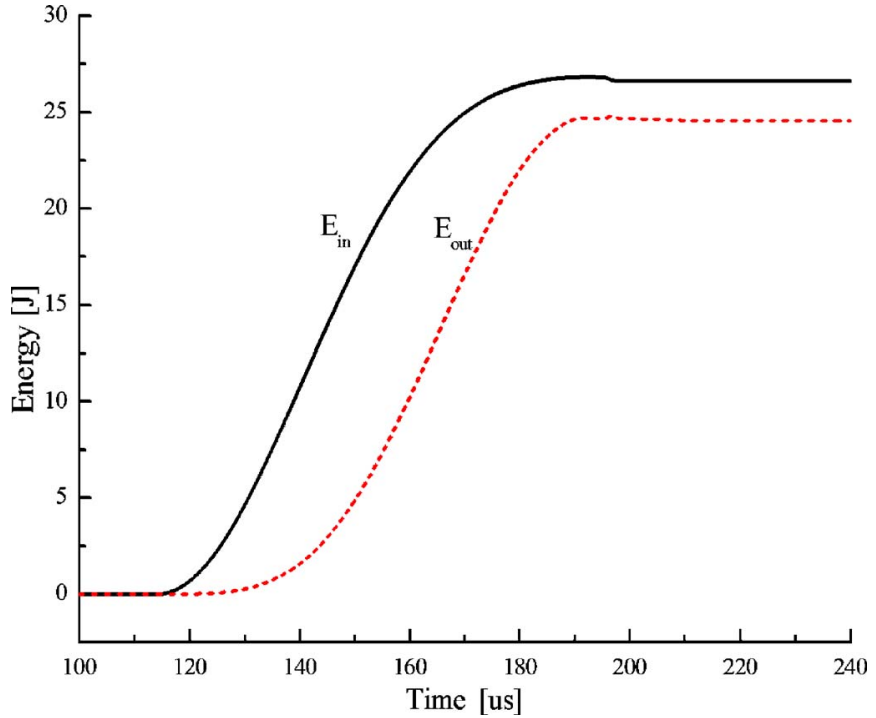

FIG. 8. (Color online) The values of $E_{\text {in }}$ and $E_{\text {out }}$ when $C_{L}=60.6 \mu \mathrm{F}$ and $C_{H}=10.37 \mathrm{nF}$.

the values of $E_{\text {in }}$ and $E_{\text {out }}$ are 26.9 and $24.7 \mathrm{~J}$, respectively; thus the energy efficiency is $91.8 \%$. The losses are mainly caused by the resistance of the primary and secondary windings, the secondary stray capacitance, and the transformer core (magnetizing energy $E_{M}$ and eddy currents). The losses caused by them were estimated to be about $1.9 \%, 2.4 \%$, $2.1 \%$, and $1.8 \%$ respectively.

\section{ACKNOWLEDGMENTS}

This work is supported by the Dutch SenterNovem IOP-EMVT programme. The authors would like to express great thanks to Mr. Ad van Iersel for his help on the construction of the transformer.

${ }^{1}$ J. Lee, C. H. Kim, J. H. Kuk, J. K. Kim, and J. W. Ahn, Proceedings of 15th IEEE International Pulsed Power Conference, June 2005 (unpublished), pp. 477-480.

${ }^{2}$ J. Zhang, J. Dickens, M. Giesselmann, J. Kim, E. Kristiansen, J. Mankowski, D. Garcia, and M. Kristiansen, Proceedings of 12th IEEE International Pulsed Power Conference, June 1999 (unpublished), pp. 704-707.

${ }^{3}$ D. Finkelsten, P. Goldberg, and J. Shuchatowitz, Rev. Sci. Instrum. 37, 159 (1966).

${ }^{4}$ M. Denicolai, Rev. Sci. Instrum. 73, 3332 (2002).

${ }^{5}$ K. Masugata, H. Saitoh, H. Maekawa, K. Shibata, and M. Shigeta, Rev. Sci. Instrum. 68, 2214 (1997).

${ }^{6}$ G. J. J. Winands, "Efficient streamer plasma generation," Ph.D. dissertation, Technische Universiteit Eindhoven, 2007; http://alexandria.tue.nl/ extra2/200710708.pdf, pp. 36-38.

${ }^{7}$ R. E. Thoms and A. J. Rosa, The analysis and design of linear circuits, 1998, pp. 485-487.

${ }^{8}$ K. Yan, "Corona plasma generation," Ph.D. dissertation, Technische Universiteit Eindhoven, 2001; http://alexandria.tue.nl/extra2/200142096.pdf, pp. 52-67.

${ }^{9}$ Z. Liu, K. Yan, G. J. J. Winands, E. J. M. Van Heesch, and A. J. M. Pemen, Rev. Sci. Instrum. 77, 073501 (2006).

${ }^{10}$ K. Yan, E. J. M. Van Heesch, S. A. Nair, and A. J. M. Pemen, J. Electrost. 5729 (2003). 